Original Research Paper

\title{
The Association between Total Mixed Ration Particle Size and Fecal Scores in Holstein Lactating Dairy Cows from Florida, USA
}

\author{
${ }^{1}$ Pedro Melendez and ${ }^{2}$ Elizabeth Roy \\ ${ }^{1}$ College of Veterinary Medicine, University of Missouri, Columbia, MO 65211, USA \\ ${ }^{2}$ Department of Large Animal Clinical Sciences, College of Veterinary Medicine, \\ University of Florida, Gainesville, FL 32610, USA
}

Article history

Received: 08-06-2015

Revised: 24-09-2015

Accepted: 02-01-2016

Corresponding Author:

Pedro Melendez

College of Veterinary

Medicine, University of

Missouri, Columbia, MO

65211, USA

Email: melendezp@missouri.edu

\begin{abstract}
The objective of this study was to determine the association between the proportion of particles greater than $19 \mathrm{~mm}$ in a total mixed ration fed to dairy cattle and their fecal score. Over a 22 day period, random feed samples were collected twice a day from a one-side barn and assessed for particle size using the Pennsylvania State Particle Separator. In addition, at each feeding sampling, the same barn was inspected and fresh feces were scored on a four point scale. Multiple regression models were developed to associate the proportion of particles $>19 \mathrm{~mm}$ with fecal scores at one, two and three days after that specific particle evaluation. Results of this observational study showed a significant relationship between particle size and fecal scores two days later. The results demonstrated a cubic polynomial effect: Fecal scores improved with increasing of the proportion of particle size $>19 \mathrm{~mm}$ at a low proportion of large particles, then it was maintained constant at intermediate proportion (10-15\%) of large particles and finally increased again with a high proportion (up to $17 \%$ ) of particle $>19 \mathrm{~mm}$.
\end{abstract}

Keywords: Dairy Cattle, Particle Size, Fecal Score

\section{Introduction}

Fiber is not very well defined as a nutrient requirement for dairy cattle. While the NRC (2001) recommends minimum values for Acid Detergent Fiber (ADF) and Neutral Detergent Fiber (NDF), there is no recommendations for type of fiber (e.g. forage NDF) and particle size or physically effective NDF (peNDF). In general, no less than $28 \%$ of a Total Mixed Ratio (TMR) should be in the form of NDF. This is further confounded by the source of NDF; the minimum total NDF required increases as the proportion of the NDF provided by forage decreases (NRC, 2001). For this reason, a diet that seems to provide adequate NDF may be in fact deficient if long particles are lacking (Grant, 1997; Suarez-Mena et al., 2013). Indeed, the value of NDF from non-forage sources is only $50 \%$ as effective as NDF from forage (Armentano and Pereira, 1997; Mertens, 1997). The improvement of chewing activity is closely related to increasing peNDF content in the diet; however, the dietary peNDF must be consumed by cows to be effective. The optimum particle size of forages needed to maintain ruminal $\mathrm{pH}$ without motivating cows to sort against long particles, has not been adequately defined (Nasrollahi et al., 2014). Consequently, inadequate fiber in the diet can lead to many problems including reduced milk yield, lower milk fat, acidosis, laminitis and displaced abomasum (Colenbrander et al., 1991; Lammers et al., 1996; Shaver, 1997; Zebeli et al., 2012). However, even having an adequate percentage of NDF provided as forage is not a guarantee that the particle size will be adequate to maintain good health. Indeed, finding an optimal balance between physically effective fiber and readily degradable carbohydrates in the diet is difficult but crucial not only for maintaining proper rumen metabolism, but also for maintaining a stable metabolic health status and enhancing the productivity of dairy cattle (Zebeli et al., 2012).

Particle size has an especially large impact on rumen physiology. Coarse pieces of forage are required in 
ruminant diets to stimulate chewing, which produce large amounts of saliva. The saliva of cattle is rich in bicarbonate and serves as an important buffer to modulate rumen function and acid production. If particle size is too small, chewing and thus saliva production will be reduced, putting the cow at risk of developing acidosis and overall poor rumen health (Allen, 1997; Heinrichs et al., 1999; Yang and Bauchemin, 2006; 2007b; Zebeli et al., 2012). Low $\mathrm{pH}$ can cause other problems in addition to changing fermentation patterns, including liver abscesses, diarrhea and laminitis (Nocek, 1997). Particle size is also important to consider in the passage rate of the feed through the rumen, which will affect its digestibility (Yang and Bauchemin, 2006). A TMR that is deficient in large particles will result in quick passage of most of the feed because of its small size. This decreases the amount of time available for the rumen microbes to ferment and digest the feed even though the rapid passage rate may increase the Dry Matter Intake (DMI). Adequate large particles will promote adequate chewing time and rumen function, which promotes a high digestion rate (Allen, 1997; Yang and Bauchemin 2007a; 2007b). However, a moderate reduction of particle size can be helpful in promoting fiber degradation in the rumen and improving the uniformity of ration. The latter is important because it results in less sorting of the feeds and improved circadian eating behavior of the cows and even lowers the risk of rumen disorders due mainly to a better distribution of the peNDF intake during the day (Zebeli et al., 2012).

One of the major problems in commercial dairies concerns the wide variability that may exist in the particle size, even from day to day. The TMR can be adequately formulated on paper, but many factors account for what ration is actually fed to the cows. One study found that the coarse portion of a TMR assessed by the Pennsylvania Particle Size Evaluator System varied from $3.2-32 \%$ over the progress of the experiment (Melendez et al., 2002). The order in which the ingredients are loaded in a mixer, the length of time spent mixing and differences in machinery or loading practices can have a drastic impact on milk production because of large particle size variation. In addition, particle sizes which are too long may encourage and enhance sorting behavior in the cattle (Suarez-Mena et al., 2013). Indeed, the sorting process among dairy cattle was greater at higher levels of initial coarse particle percentage; for each $1 \%$ increase in initial coarse portion, there was a $4 \%$ increase in the residual feed (weigh-back) coarse portion (Melendez et al., 2002).

Fecal characteristics and consistency have been used as tools to evaluate digestive health and effectiveness of feeding programs in lactating dairy cattle. Failure of the rumen to selectively retain particles could result in passage of potentially digestible feed particles to the small and large intestine, which, consequently, might cause feces with a loose and foamy consistency. On the contrary, a firm feces characteristic indicates less hindgut fermentation and a low intake of dietary protein (Lean et al., 2014).

One study found that cows on a low fiber diet had more liquid feces than cows on a high fiber diet (Ireland-Perry and Starling, 1993). However, this study only evaluated fiber based on the chemical composition of the diet. In addition, this is the only scientific study in the U.S. proposing a fecal score to be used as an objective tool to evaluate the digestive physiology of dairy cattle. In a study conducted in Sweden as part of a Master of Science thesis (Mgbeahuruike, 2007), increased intake of forage NDF and increased dietary concentration of NDF increased fecal NDF concentration and fecal consistency. However, there is a lack of experimental data looking for a relationship between particle size of a TMR and fecal characteristics of cows eating that particular diet. The hypothesis of this study was that fecal scores will change as the proportion of coarse particles $(>19 \mathrm{~mm})$ varies. The objective of this study was to evaluate the association between the proportion of particle size $>19 \mathrm{~mm}$ in a lactating dairy cattle TMR and a proposed fecal score from cows eating that particular diet under commercial settings in a Florida dairy farm, USA, during a period of one month.

\section{Materials and Methods}

\section{Dairy farm}

The study was conducted at the Dairy Research Unit at the University of Florida. The farm is located in Alachua County in North Central Florida. The latitude and longitude of the farm is: $29^{\circ} 39^{\prime} 5^{\prime \prime} \mathrm{N} / 82^{\circ} 19^{\prime} 30^{\prime \prime} \mathrm{W}$.

The dairy consisted of 550 Holstein dairy cows milked twice daily with a rolling herd average milk production of $10,000 \mathrm{~kg}$. Transition dairy cows (21 days before expected parturition and 21 days postpartum) were housed in a pre- and postpartum dry-lot system. Lactating and dry cows were fed a TMR to meet or exceed nutrient requirements of the NRC (2001). The pre-partum diet contained anionic salts to prevent hypocalcemia and other calving-related disorders.

Cows calved in the prepartum transition lot and were moved immediately after calving to a processing pen where they were scored for body condition (scale 1-5), udder edema and reproductive tract status; i.e., lacerations or the presence of Retained Fetal Membranes (RFM). If cows were suspected of having RFM they stayed $24 \mathrm{~h}$ in a hospital barn until RFM was confirmed. After that, cows were moved to a postpartum transition pen and monitored for development of metritis during the first milking within the first 10 days postpartum. At 21 days postpartum cows were moved to a high 
producing lactating group, housed in a free stall barn with fans and sprinklers provided at the feed bunk.

\section{Study Design}

One side of one of the free stall barns with 74 midlactation cows (100 to 200 days in milk) were used for this study. Over a 22 day period, a random fresh TMR sample was taken twice per day, at the morning and evening feedings. Samples were obtained by collecting 10 representative samples approximately every 10 meters by grabbing a handful of TMR along the 100 meter feed bunk. Each sample was carefully placed in a plastic bag without shaking the hand to avoid losses of any fraction of the TMR. In Table 1, diet ingredients and nutrient composition of the TMR is shown.

\section{Sample Processing}

The samples were processed using the modified Penn State Particle Separator (PSPS). This device consists of 3 sieves and a bottom pan with no holes. The top three screens have rounded holes which are 19,8 and $1.18 \mathrm{~mm}$ in diameter, respectively (Kononoff et al., 2003). Samples were processed immediately after collection. All ten handful samples were commingled in the bag. This representative sample was mixed until homogenized. One hundred grams was taken out, weighed and used for processing. The particle size evaluator was used according to the instructions outlined by the PSPS system developers (Kononoff et al., 2003).

\section{Fecal Score Evaluation}

Following sample processing, approximately 45 to 60 minutes after feeding the TMR, fresh feces were evaluated and scored according to the following scale adapted from Ireland-Perry and Stallings (1993):

1.0: Liquid consistency, splatters on impact, spreads readily, amorphous shape and more than $50 \mathrm{~cm}$ in diameter

1.5: Less liquid consistency, splatters on impact, spreads readily, less amorphous shape and less than $50 \mathrm{~cm}$ in diameter

2.0: May pile slightly and spreads and splatters moderately on impact and setting, rounded and more than $30 \mathrm{~cm}$ in diameter

2.5: Pile slightly and spreads and splatters moderately on impact and setting, more rounded and less than 30 $\mathrm{cm}$ in diameter

3.0: Firm but not hard, piles but spreads slightly on impact and setting, rounded and less than $30 \mathrm{~cm}$ in diameter

3.5: Firm and hard, piles but still spreads slightly on impact and setting, rounded and less than $30 \mathrm{~cm}$ in diameter

4.0: Hard, dry appearance, original form not distorted on impact and setting, rounded, less than $30 \mathrm{~cm}$ in diameter

Figure 3 shows examples of all scores from 1- 4. All sample processing and fecal scoring was conducted by the same person to minimize variation.

Table 1. Diet ingredients and nutritional composition of the mid-lactation cow diet

\begin{tabular}{|c|c|}
\hline TMR feed ingredients & Percentage (\%) Dry Matter Basis \\
\hline Alfalfa Hay & 9.87 \\
\hline Bermudagrass Hay & 2.48 \\
\hline Corn silage & 20.20 \\
\hline Sorghum silage & 11.73 \\
\hline Cottonseed whole & 6.73 \\
\hline Corn hominy & 16.82 \\
\hline Citrus pulp & 5.29 \\
\hline Soybean meal 48 & 7.20 \\
\hline Soy plus & 5.10 \\
\hline Cottonseed meal & 2.82 \\
\hline Molasses & 3.48 \\
\hline Cottonseed hulls & 4.00 \\
\hline Lactating minerals and vitamins & 4.28 \\
\hline \multicolumn{2}{|l|}{ Nutritional Composition of TMR } \\
\hline Dry Matter $(\%)$ & 43.40 \\
\hline $\mathrm{CP}(\% \mathrm{DM})^{1}$ & 16.00 \\
\hline UndegP(\%CP $)$ & 30.34 \\
\hline $\operatorname{DegP}(\% \mathrm{CP})^{2}$ & 69.66 \\
\hline $\mathrm{ADF}(\% \mathrm{DM})^{1}$ & 25.60 \\
\hline $\mathrm{NDF}(\% \mathrm{DM})^{1}$ & 37.40 \\
\hline $\mathrm{Ca}(\% \mathrm{DM})^{1}$ & 0.61 \\
\hline $\mathrm{P}(\% \mathrm{DM})^{1}$ & 0.32 \\
\hline $\mathrm{Mg}(\% \mathrm{DM})^{1}$ & 0.29 \\
\hline $\mathrm{K}(\% \mathrm{DM})^{1}$ & 1.55 \\
\hline $\mathrm{Na}(\% \mathrm{DM})^{1}$ & 0.54 \\
\hline
\end{tabular}

${ }^{1}$ Laboratory nutritional analysis; ${ }^{2}$ Values from feed composition tables 


\section{Statistical Analyses}

The proportion of each fraction from the particle size evaluator was calculated for each feeding. The frequency count of each fecal score was recorded at each feeding time. A mean proportional fecal score was calculated for each counting period. Several multivariable regression models were conducted to associate the different fractions of the particle size analysis with fecal scores up to three days subsequent to that particle size determination. For example, the proportion of coarse particles in a feed sample collected on Monday morning was correlated with fecal scores recorded Tuesday morning ( $24 \mathrm{~h}$ later), Wednesday morning (48 h later) and Thursday morning $(72 \mathrm{~h}$ later $)$. This criteria assumption was based on feed retention time in the rumen, which it may vary from 30 to $50 \mathrm{~h}$ after eating (Casper et al., 1999; Luginbuhl et al., 1994; Zebeli et al., 2012; Lean et al., 2014).

The best model predictor with the highest Rsquared is reported and further discussed. Statistical analysis was conducted using the GLM procedure of SAS 9.1 (SAS, 2003).

\section{Results}

In Table 2, descriptive statistics for different fractions of the PSPS and fecal scores are shown. During the study period, the mean, minimum and maximum fresh coarse fraction was $10.79,5.0$ and $17 \%$, respectively. For fecal score, the mean, minimum and maximum values were $2.34,2.23$ and 2.48 , respectively. Figure 1 illustrates the total number of fecal piles scored across the 22 day period $(n=1049)$. The great majority of the feces received a score of 2.5 .

The best model obtained in the present study considered only fresh coarse fraction as a predictor of fecal score 2 days after the fresh TMR was consumed. In Fig. 2, the relationship between fresh coarse particle proportion from the PSPS and fecal score 2 days after that TMR was fed is shown. There was a polynomial cubic effect for fecal score as a function of fresh coarse fraction. The best fitted equation was: Fecal score $=$ $1.16+0.3312 X-0.0299 X^{2}+0.0009 X^{3}$. Almost $20 \%\left(r^{2}\right.$ $=0.1996)$ of the variability in fecal scores 2 days after the TMR evaluation was explained by the fresh coarse fraction (particles $>19 \mathrm{~mm}$ ) of that particular TMR.

Table 2. Descriptive statistics for the four fractions from the PSPS and mean fecal scores during the 22 day-period

\begin{tabular}{llllll}
\hline & $\mathrm{LF}^{1}(\%)$ & $\mathrm{MF}^{2}(\%)$ & $\mathrm{SF}^{3}(\mathbf{\%})$ & $\mathrm{FF}^{4}(\%)$ & Fecal Score $($ scale 1-4) \\
\hline Mean & 10.79 & 42.30 & 31.35 & 15.56 & 2.34 \\
SEM & 0.47 & 0.50 & 0.40 & 0.48 & 0.01 \\
Median & 11 & 42 & 31 & 16 & 2.33 \\
SD & 3.07 & 3.26 & 2.64 & 3.14 & 0.07 \\
Minimum & 5 & 37 & 26 & 7 & 2.23 \\
Maximum & 17 & 49 & 37 & 21 & 2.48 \\
Count & 43 & 43 & 43 & 43 & 1049 \\
\hline
\end{tabular}

${ }^{1}$ LF: Long Fraction, $>19 \mathrm{~mm} ;{ }^{2} \mathrm{MF}$ : Medium Fraction, 8.0-19 mm; ${ }^{3} \mathrm{SF}$ : Small Fraction, 1.18-8.0 mm; ${ }^{4}$ FF: Fine Fraction, $<1.18 \mathrm{~mm}$

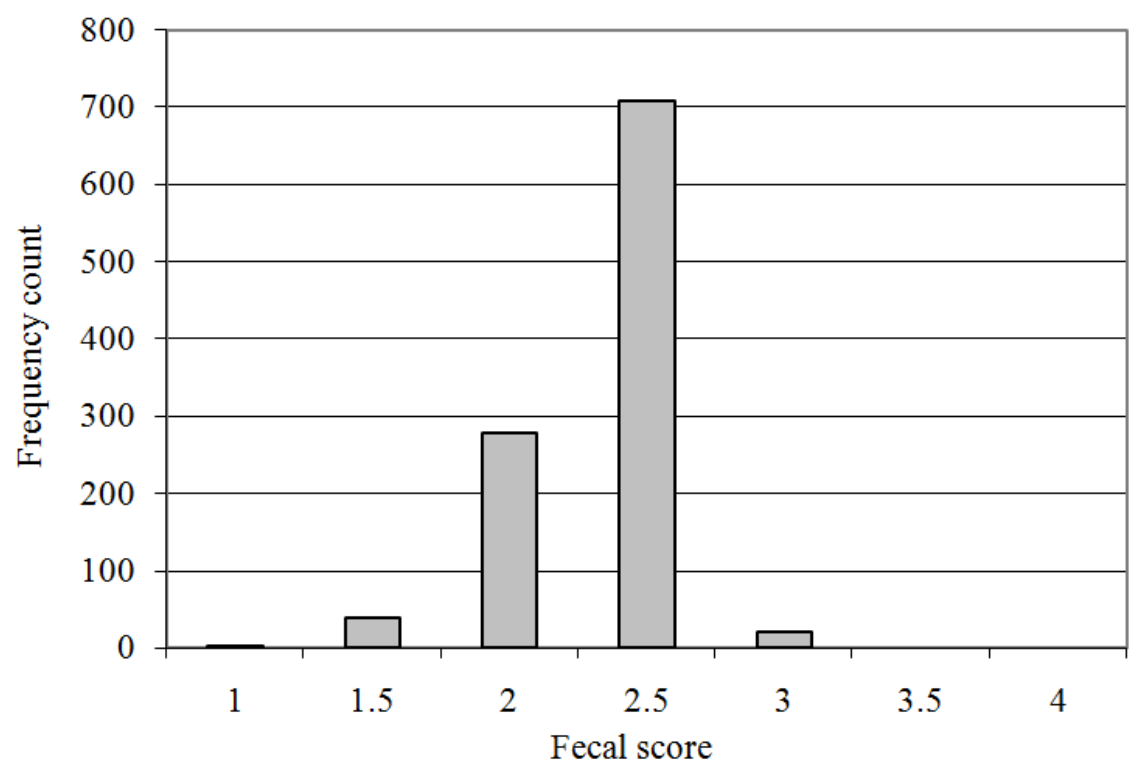

Fig. 1. Frequency count for each fecal score over the 22 day- period $(n=1049)$ 




Fig. 2. The relationship between fresh coarse particle size proportion from the PSPS and fecal score 2 days after that evaluated TMR in mid lactation Holstein cows during a period of 22 days. Note the cubic function (third order of polynomial effect) of fecal score as fresh coarse fraction increases. Fecal score $=1.16+0.3312 \mathrm{X}-0.0299 \mathrm{X}^{2}+0.0009 \mathrm{X}^{3} .\left(\mathrm{r}^{2}=0.1996\right)$

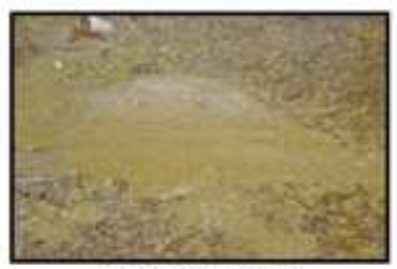

Fecal Score 1.0

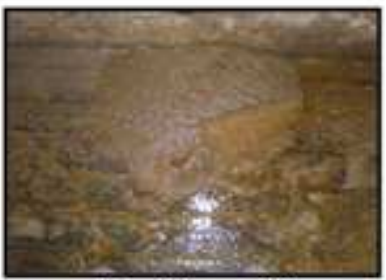

Fecal Score 2.0

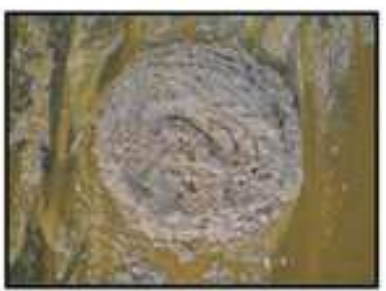

Fecal Score 3.0

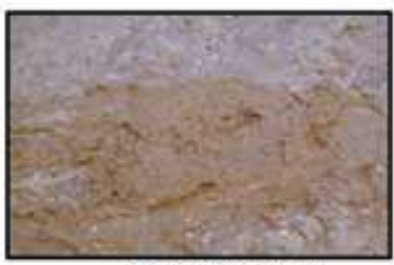

Fecal Score 1.5



Fecal Score 2.5

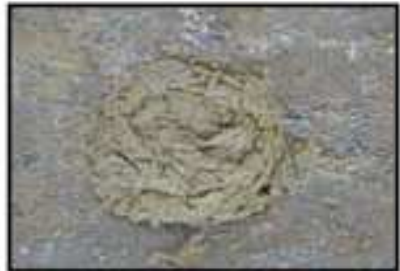

Fecal Score 3.5

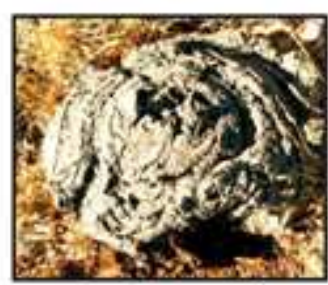

Fecal Score 4.0

Fig. 3. Fecal scores 1 to 4 in a 0.5 increment scale 
In Fig. 3, pictures of the different fecal scores based on this research definition are shown.

\section{Discussion}

Notwithstanding from the sampling protocol of the TMR for particle size evaluation, there was no intervention in the group of animals under examination. Indeed, this was merely an observational study conducted in a dairy herd managed under commercial conditions in a subtropical environment intending to relate the physical characteristics of a daily TMR and the characteristic of feces produced by the animals consuming that particular diet. Based on an extensive literature review on the topic, to our knowledge this is the first report associating the proportion of particles larger than $19 \mathrm{~mm}$ of a TMR and fecal characteristics of lactating dairy cows.

A fecal scoring system was developed based on a unique scientific article that defined fecal characteristics and related it to the chemical composition of the diet. Several articles published in extension magazines have described fecal scoring systems; however, due to a lack of sufficient peer reviewed scientific research; it was difficult to homogenize criteria to develop the scoring system used in the present study. The score was adapted from the study of Ireland-Perry and Stallings (1993) and was based on consistency, physical form and shape of the fecal material. In addition, the scoring system was validated by a preliminary pilot study, in which both authors of this article individually scored several fecal samples on the same farm until there was a consistent matching of scores with no more than a 0.5 point difference. One of the strengths of this study is that TMR sampling and processing and fecal score determination was conducted entirely by the same person (one of the authors). This definitely reduced variability in fecal scoring and particle size evaluation.

Since the first published study in 1996 (Lammers et al., 1996), the use of the PSPS has become a popular method for evaluating particle size in dairy cattle diets (Kononoff et al., 2003). Two trials conducted under practical conditions using the same methodology demonstrated that cows can sort ingredients of a TMR and perform differently in milk production depending on the original proportion of the different fractions obtained under the PSPS methodology (Melendez et al., 2002; 2006). Several more controlled studies have demonstrated that chewing activity and saliva production increased when forage NDF and proportion of particle size $>19 \mathrm{~mm}$ increased in the diet. This effect has a direct impact on rumen $\mathrm{pH}$ and health (Allen, 1997; Armentano and Pereira, 1997; Heinrichs et al., 1999; Goff, 2006; Zebeli et al., 2012; Lean et al., 2014). Indeed, rumen acidosis is a frequent harmful condition related to low effective fiber in diet (Nocek, 1997; Yang and Bauchemin, 2006; Lean et al., 2014).

In a previous study conducted at the same dairy farm (Melendez et al., 2002), the range of the proportion of the coarse fraction of a fresh TMR evaluated during 30 days was between 3.2 and $32 \%$, which can be considered as an indicator of poor and inconsistent management of the TMR preparation. In the present study, the range was between 5 and $17 \%$, a more consistent value for the proportion of the coarse fraction. Although there was low variability, it was sufficient to find an association between the proportion of coarse particles and fecal score 2 days after the TMR was fed. Almost $20 \%$ of the variability in fecal score was fully explained by the variation in the coarse proportion of the TMR offered $48 \mathrm{~h}$ before. The association was not linear and fecal score had a cubic response as a function of the proportion of coarse fraction obtained from the PSPS methodology. The rest of the models looking for an association between particle size and fecal score both one and three days after feeding that particular TMR were found to be not significant. The reasons for the cubic response of fecal score $48 \mathrm{~h}$ after the TMR consumption can be inferred from natural sorting behavior that occurs in dairy cows. At relatively low levels of coarse particles, an increase in the proportion of particles $>19 \mathrm{~mm}$ was associated with an increase in fecal scores. However, as the coarse fraction of the TMR reached levels between 12 to $15 \%$, fecal scores were maintained constant around 2.35. This may be because intermediate levels of a coarse fraction can induce a more stable digestive function maintaining a constant fecal consistency over time. Indeed, a moderate forage particle size can be helpful in promoting fiber degradation in the rumen and improving the uniformity of ration. This is important because it results in less sorting of the feeds and improved eating behavior of the cows and even lowers the risk of rumen disorders due mainly to a better distribution of the peNDF intake during the day (Zebeli et al., 2012). Interestingly, in the present study, the daily average fecal score was always above 2.2, which means feces were still in a pile and rounded with adequate consistency.

As the coarse fraction continues to increase above $15 \%$ and becomes relatively high, fecal scores increased. Even though the cows may be able to sort more effectively at this level of fiber, they will still eat proportionally more of the coarse portion of the TMR to maintain their DMI and normal rumen function. In addition, increased intake of forage NDF increased fecal consistency (Mgbeahuruike, 2007). Perhaps, the upper limit of the coarse fraction in the present study $(17 \%)$ is still acceptable to maintain a proper eating behavior with a minimum sorting process. 


\section{Conclusion}

The increment of the proportion of large size particles in the TMR significantly was associated to an improvement of fecal score in lactating dairy cattle, up to a certain point. If the coarse fraction was between 10 to $15 \%$, fecal scores were maintained. However, when coarse fraction was beyond $15 \%$ to a maximum of $17 \%$, fecal score began to increase, implying this level of particle size $>19 \mathrm{~mm}$ is still acceptable for an adequate rumen and digestive function.

\section{Acknowledgement}

The authors want to thanks to Merck-Merial for providing funding and the Dairy Research Unit of the University of Florida for allowing us to conduct this trial.

\section{Funding Information}

The authors would like to acknowledge the University of Missouri for funding this manuscript.

\section{Author's Contributions}

Elizabeth Roy: Study design, data analysis, manuscript writing.

Pedro Melendez: Study design, sampling, data recording, manuscript editing.

\section{Ethics}

The authors declare there are no ethical issues related to this observational study.

\section{References}

Allen, M.S., 1997. Relationship between fermentation acid production in the rumen and the requirement for physically effective fiber. J. Dairy Sci., 80: 1447-1462. DOI: $10.3168 /$ jds.S0022-0302(97)76074-0

Armentano, L. and M. Pereira, 1997. Measuring the effectiveness of fiber by animal response trials. J. Dairy Sci., 80: 1416-1425. DOI: $10.3168 / j d s . S 0022-0302(97) 76071-5$

Casper, D.P., H.A. Maiga, M.J. Brouk and D.J. Schingoethe, 1999. Synchronization of carbohydrate and protein sources on fermentation and passage rates in dairy cows. J. Dairy Sci., 82: 1779-1790. DOI: $10.3168 /$ jds.S0022-0302(99)75408-1

Colenbrander, V.F., C.H. Noller and R.J. Grant, 1991. Effect of fiber content and particle size of alfalfa silage on performance and chewing behavior. J. Dairy Sci., 74: 2681-2690.

DOI: $10.3168 /$ jds.S0022-0302(91)78446-4

Goff, J.P., 2006. Major advances in our understanding of nutritional influences on bovine health. J. Dairy Sci., 89: $1292-1301$.

DOI: $10.3168 /$ jds.S0022-0302(06)72197-X
Grant, R.J., 1997. Interactions among forages and nonforage fiber sources. J. Dairy Sci., 80: 1438-1446. DOI: $10.3168 /$ jds.S0022-0302(97)76073-9

Heinrichs, A.J., D.R. Buckmaster and B.P. Lamers, 1999. Processing, mixing and particle size reduction of forages for dairy cattle. J. Anim. Sci., 77: 180-186. PMID: 10064042

Ireland-Perry, R.L. and C.C. Stallings, 1993. Fecal consistency as related to dietary composition in lactating Holstein cows. J. Dairy Sci., 76: 1074-1082. PMID: 8387550

Kononoff, P.J., A.J. Heinrichs and D.R. Buckmaster, 2003. Modification of the Penn state forage and total mixed ration particle separator and the effects of moisture content on its measurements. J. Dairy Sci., 86: 1858-1863. DOI: 10.3168/jds.S0022-0302(03)73773-4

Lammers, B.P., D.R. Buckmaster and A.J. Heinrichs, 1996. A simple method for the analysis of particle sizes of forage and total mixed rations. J. Dairy Sci., 79: 922-928. DOI: 10.3168/jds.S0022-0302(96)76442-1

Lean, I.J., H.M. Golder and M.B. Hall, 2014. Feeding, evaluating and controlling rumen function. Vet. Clin. North Am. Food Anim. Pract., 30: 539-575. DOI: 10.1016/j.cvfa.2014.07.003

Luginbuhl, J.M., K.R. Pond and J.C. Burns, 1994. Whole-tract digesta kinetics and comparison of techniques for the estimation of fecal output in steers fed coastal bermudagrass hay at four levels of intake. J. Anim. Sci., 72: 201-211. PMID: 8138490

Mgbeahuruike, A.C., 2007. Fecal characteristics and production of dairy cows in early lactation. MSc Thesis, Swedish University of Agricultural Sciences, Skara, Sweden.

Melendez, P., N. Back, S. Lanhart and A. Donovan, 2006. Particle size evaluation and its association with feed intake, milk yield and chewing activity in mid-lactation Holstein cows. Bov. Pract., 40: 39-45.

Melendez, P., O. Rodriguez, S. Madrid and A. Donovan, 2002. The association between forage particle size at initial feeding and the weigh-back and chewing activity in dairy cattle. Bov. Pract., 36: 66-70.

Mertens, D.R., 1997. Creating a system for meeting the fiber requirements of dairy cows. J. Dairy Sci., 80: 1463-1481. DOI: $10.3168 /$ jds.S0022-0302(97)76075-2

Nasrollahi, S.M., G.R. Ghorbani, M. Khorvash and W.Z. Yang. 2014. Effects of grain source and marginal change in Lucerne hay particle size on feed sorting, eating behaviour, chewing activity and milk production in mid-lactation Holstein dairy cows. J. Anim. Physiol. Anim. Nutr., 98: 1110-1116. DOI: 10.1111/jpn. 12185

NRC, 2001. Nutrient Requirements of Dairy Cattle. 7th Edn., National Research Council, Washington, ISBN-10: 0309069971, pp: 408. 
Nocek, J.E., 1997. Bovine acidosis: Implications on laminitis. J. Dairy Sci., 80: 1005-1028.

DOI: $10.3168 /$ jds.S0022-0302(97)76026-0

SAS, 2003. SAS/STAT Software: Change and enhancements through release 9.1 for windows. SAS Inst. Inc., Cary, NC.

Shaver, R.D., 1997. Nutritional risk factors in the etiology of left displaced abomasum in dairy cows: A review. J. Dairy Sci., 80: 2449-2453. DOI: $10.3168 /$ jds.S0022-0302(97)76197-6

Suarez-Mena, F.X., G.I. Zanton and A.J. Heinrichs, 2013. Effect of forage particle length on rumen fermentation, sorting and chewing activity of latelactation and non-lactating dairy cows. Animal, 7: 272-278. DOI: $10.1017 /$ S1751731112001565

Yang, W.Z. and K.A. Beauchemin, 2007a. Altering physically effective fiber intake through forage proportion and particle length: Digestion and milk production. J. Dairy Sci., 90: 3410-3421.

DOI: $10.3168 /$ jds.2006-818
Yang, W.Z. and K.A. Beauchemin, 2007b. Altering physically effective fiber intake through forage proportion and particle length: Chewing and ruminal pH. J. Dairy Sci., 90: 2826-2838. DOI: $10.3168 /$ jds.2007-0032

Yang, W.Z. and K.A. Beauchemin, 2006. Physically effective fiber: Method of determination and effects on chewing, ruminal acidosis and digestion by dairy cows. J. Dariy Sci., 89: 2618-2633. DOI: $10.3168 /$ jds.S0022-0302(06)72339-6

Zebeli, Q., J.R. Aschenbach, M. Tafaj, J. Boguhn and B.N. Ametaj et al., 2012. Invited review: Role of physically effective fiber and estimation of dietary fiber adequacy in high-producing dairy cattle. J. Dairy Sci., 95: 1041-1056.

DOI: $10.3168 /$ jds.2011-4421 